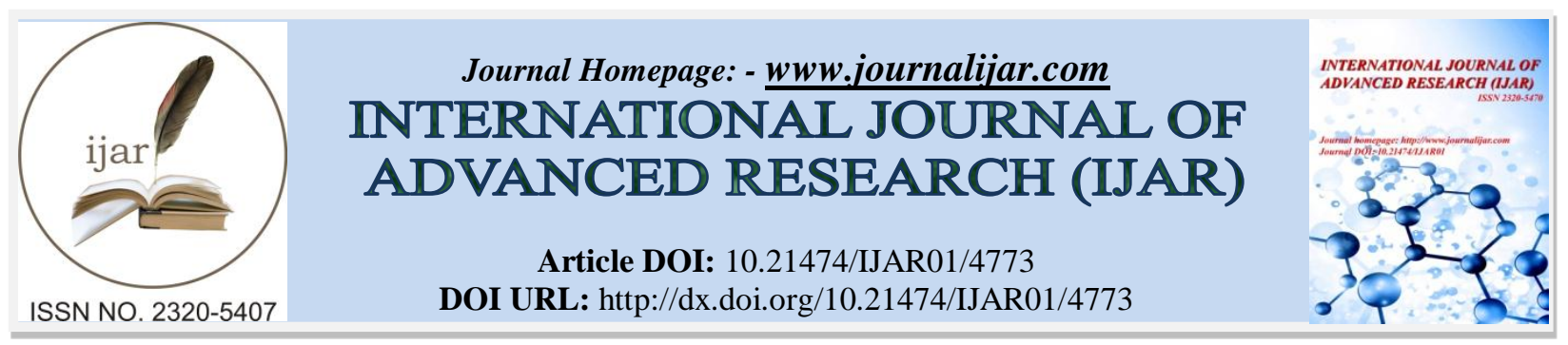

RESEARCH ARTICLE

\title{
IN VITRO ANTIOXIDANT ACTIVITIES OF ETHANOLIC EXTRACT AND TRITERPENOID FRACTION OF GARCINIA KOLA STEM BARK AND INHIBITION OF ARSENIC-INDUCED RAT LIVER AND KIDNEY MITOCHONDRIAL MEMBRANE PERMEABILITY TRANSITIONS.
}

*Godswill N. Anyasor and Adesola J. Ajagunna.

Department of Biochemistry, Benjamin S. Carson (Snr.) School of Medicine, College of Health and Medical Sciences, Babcock University, Ilisan-Remo, Ogun State, Nigeria.

\section{Manuscript Info}

\section{Manuscript History}

Received: 7 May 2017

Published: July 2017

Key words:-

Arsenic; antioxidant; Garcinia kola; mitochondria; stem
Final Accepted: 9 June 2017

\section{Abstract}

This study was designed to investigate the in vitro antioxidant activities and inhibitory effects of $G$. kola stem bark ethanolic extract (EEGK) and triterpenoid fraction (TFGK) on arsenic-induced liver and kidney mitochondrial membrane permeability transitions (MMPTs). DPPH (1-1-diphenyl 2-picryl hydrazyl), hydrogen peroxide scavenging (HPSA), hydroxyl radical scavenging (HRSA) and total antioxidant capacity (TAC) assays were performed to determine antioxidant activity in vitro. Rat liver and kidney mitochondrial fractions were isolated using differential centrifugation technique while MMPT assay was performed using spectrophotometric method. Results showed that EEGK had a significantly $(\mathrm{P}<0.05)$ high DPPH, HPSA, HRSA and TAC scavenging activity than TFGK. However, 30 $\mu \mathrm{g} / \mathrm{mL}$ TFGK significantly $(\mathrm{P}<0.05)$ inhibited arsenic-induced liver and kidney MMPT by $92.59 \%$ and $88.89 \%$ when compared with EEGK $(70.37 \%$ and $66.67 \%)$ and standard spermine $(81.48 \%$ and $77.78 \%$ ). Thus, data from this study indicated that ethanolic extract of G. kola stem bark exhibited higher antioxidant activity in vitro while TFGK substantially inhibited arsenic-induced liver and kidney mitochondrial membrane permeability transitions.

Copy Right, IJAR, 2017,. All rights reserved.

\section{Introduction:-}

Sodium arsenic $\left(\mathrm{NaAsO}_{2}\right)$ is regarded as a high priority toxic contaminant due to its toxic effects in human (Bishayi, 2000). In the environment, inorganic arsenic exits as arsenate (pentavalent, $\mathrm{As}^{5+}$ ) and arsenite (trivalent, $\mathrm{As}^{3+}$ ) and are readily interconvertible in aquatic environment through redox and methylation reactions. Arsenite toxicity is known to be higher than arsenate under in vitro and in vivo conditions (Kulp et al., 2004; WHO, 2004). Arsenic contaminant in the environment has been through natural and man-made sources, including drinking water, agricultural pesticides, coal fired power plants, glassware manufacturing, wood preservatives, smelting and cosmetic industries (Kapaj et al., 2006; Flora et al., 2009).

Ingested arsenic is readily absorbed through the gastrointestinal tract, and distributed through blood circulation into liver, kidney, heart, lung, gastrointestinal tract and spleen leading to arsenicosis (Kitchin, 2001). On a molecular level, the mechanism of arsenic toxicity is through binding to protein free thiol groups (Tapio and Grosche, 2006). This leads to enhanced production of toxic oxygen radicals, inhibition of numerous cellular enzymes, DNA repair

Corresponding Author:- Godswill N. Anyasor. 
mechanisms interference, alteration of gene expression and oxidative stress (Shi et al., 2004; Jomova et al., 2011). Experimental findings have shown that mitochondrial reactive oxygen species are contributory to the toxicity induced by arsenic in flies, worms, mouse and human liver (Schmeisser et al., 2013; Chavan et al., 2017). In addition, hepatic damage and renal dysfunction have been reported as the most common complication associated with chronic arsenic exposure (Santra et al., 2000).

Mitochondria are known to serve as a target site for arsenic toxicity through the generation of toxic oxygen radicals and participation in the initiation of the apoptotic caspase-cascade. This process is associated with the formation of mitochondrial membrane permeability transition (MMPT) (Selvaraj et al., 2013). MMPT is a molecular events caused by opening of the inner mitochondrial membrane voltage-dependent anion channel known as the permeability transition pore under certain conditions including noxious agents, $\mathrm{Ca}^{2+}$ overload and oxidative stress. It is a sudden increase of inner mitochondrial permeability to solutes with a molecular mass up to $1.5 \mathrm{kDa}$ and has been implicated in apoptotic or necrotic pathways leading to neurodegeneration (Bustamante et al., 2005; Rao et al., 2014).

The conventional treatments for arsenic-induced toxicity in patients are thiol containing chelating agents such as British Anti Lewisite (BAL; 2,3-dimercaprol), meso 2,3-dimercaptosuccinic acid (DMSA) and 2,3 dimercaptopropane-1-sulfonate (DMPS) (Flora et al., 2009; Chandranayagam et al., 2013). However, the use of these drugs is still limited due to accompanying adverse effects. In contrast to synthetic drugs, medicinal plants are usually less toxic with fewer side effects (Nasri and Shirzad, 2013).

Garcinia kola Heckel is a dicotyledonous plant belonging to the family of Clusiaceae. It is a perennial crop that is distributed throughout West and Central Africa (Iwu et al, 2009; Farombi and Owoeye, 2011). G. kola is a medium sized evergreen tree that is about $15-17 \mathrm{~m}$ tall with a fairly narrow crown. The leaves are $6-14 \mathrm{~cm}$ long and $2-6$ $\mathrm{cm}$ across. The small flowers are covered with short red hairs (Iwu, 1993). The fruit is a drupe of $5-10 \mathrm{~cm}$ in diameter and weighs $30-50 \mathrm{~g}$. It is usually smooth and contains a yellowish red pulp. The fruit changes color during maturation from green to orange, and each fruit contains 1 - 4 seeds (Juliana et al., 2006).

G. kola has been referred to as a "wonder plant" because every part of it has important medicinal properties (Farombi and Owoeye, 2011). It is commonly called "bitter cola" or "male kola" due to the reported aphrodisiac property. G. kola stem bark is used in folklore remedies as a purgative and the latex is externally applied to fresh wounds to prevent sepsis. A decoction of G. kola stem bark is used as therapy for the treatment of dysmenorrhea, fever, inflammation and burns (Adesina et al, 1995).

G. kola stem bark contains a complex mixture of phenolic compounds such as biflavonoids, xanthines and benzophenone, kolanone, kolaflavanone and garcinia flavanone (Iwu, 1993). Data obtained from our laboratory through gas chromatography-mass spectrometry analysis showed the presence of fatty acids, oxalic acid, erucic acid and13-docosenoic acid in the ethanolic extract of G. kola stem bark while its triterpenoid fraction contained 3,4dimethyl-2,5-dihydrofuran, 9,15-octadecadienoic acid, oleic acid, 9,12-octadecadienal, trans-farnesol and brassidic acid previously known to elicit hepatoprotective and nephroprotective properties. Therefore, this study was designed to investigate the antioxidant activities and inhibitory effects of ethanolic extract and triterpenoid fraction of $G$. kola stem bark on arsenic-induced liver and kidney MMPTs. This was carried out with the rationale to proffer scientific explanation to the ameliorative effects of $G$. kola stem bark fraction against metal-induced tissue damage.

\section{Materials and Methods:-}

Plant material collection and Identification:-

Stem barks of G. kola were collected from an Ilishan farm in Ogun State and authenticated at the Herbarium of the Forestry Research Institute of Nigeria, Jericho, Ibadan, Oyo State with voucher number FHI/110398.

\section{Plant processing and extraction:-}

Stem barks of $G$. kola were thoroughly washed to remove debris, chopped and oven-dried at $40^{\circ} \mathrm{C}$. Dried stem barks were pulverized, using a mechanical blender and $200 \mathrm{~g}$ was soaked with $1.6 \mathrm{~L} 70 \%$ ethanol and mixed intermittently for $48 \mathrm{~h}$ at room temperature. The suspension was filtered using Whatman No. 1 filter paper and concentrated using a rotary evaporator (Buchi Rotavapor RE, Switzerland) at $40^{\circ} \mathrm{C}$ and stored in a refrigerator until further use. Furthermore, triterpenoid fraction of G. kola stem bark was prepared according to the method described by Pramod et al. (2006). Pulverized G. kola stem bark ( $250 \mathrm{~g}$ ) was soaked with $95 \%$ ethanol and the suspension was mixed 
intermittently for 7 days at room temperature. Subsequently, the extract was filtered using Whatman No.1 filter paper. The filtrate obtained was concentrated using a rotary evaporator (Buchi Rotavapor RE, Switzerland) at $40^{\circ} \mathrm{C}$ to obtain an ethanolic extract. The obtained ethanolic extract was further partitioned between ethyl acetate and water. Ethyl acetate fraction was further partitioned using n-hexane to isolate triterpenoids. Ethanolic extract and triterpenoid fraction of $G$. kola stem bark were stored in a refrigerator until further use.

\section{Animals:-}

Five male albino rats (Wistar strain) weighing between 150 - $200 \mathrm{~g}$ were purchased from an inbred colony at Babcock University Animal Facility. Animals were allowed to acclimatize in aerated cages under a natural light condition at room temperature and fed with commercial pelleted diet and water ad libitum for two weeks. All animal experiments and protocols conformed to the National Institute of Health Guide for the Care and Use of Laboratory Animals (2011). Ethical clearance with certificate number BUHREC227/16 was obtained from the Babcock University Health Research Ethics Committee.

\section{Quantitative phytochemical analysis of G. kola stem bark extract/fraction:-}

Total phenolic content was determined according to the method described by Singleton et al. (1999). Total flavonoid content was by Aluminum chloride method as described by Ordonez et al. (2006). Tannin content was determined according to the modified vanillin- $\mathrm{HCl}$ methanol method as described by Noha (2011). Saponin content was determined according to the method described by Okwu and Josiah (2006). Alkaloid content was determined using the method described by Onyilagba and Islam (2011).

\section{Determination of G. kola stem bark extract/fraction antioxidant activity using in vitro methods:-}

DPPH radical scavenging activity was determined using the method described by Mensor et al. (2001). Hydrogen peroxide scavenging activity was measured according to the method described by Ruch et al. (1989). Hydroxyl radical scavenging activity of $G$. kola stem bark extract/fraction was measured according to the method of Halliwell et al. (1987). Total antioxidant capacity of the extract/fraction was determined using phosphomolybdate method as described by Priesto et al. (1999).

\section{Liver and kidney Mitochondrial fractions isolation:-}

Mitochondrial fractions from the liver and kidneys of rats were isolated using conventional differential centrifugation technique as described by Hogeboom et al. (1948). Rat liver and kidney mitochondrial fractions were isolated in a buffer solution containing $210 \mathrm{mM}$ mannitol, $70 \mathrm{mM}$ sucrose, $5 \mathrm{mM}$ 2-(4-[2-hydroxyethyl] piperazin-1yl) ethanesulfonic acid (HEPES) at $\mathrm{pH} 7.4$ and $1 \mathrm{mM}$ ethylene glycol tetraacetic acid (EGTA). Mitochondrial protein content was determined by Folin-Ciocateau method using bovine serum albumin as standard protein as described by Lowry et al. (1951).

\section{Assessment of mitochondrial membrane permeability transition:-}

Mitochondrial membrane permeability transition was assessed according to the method of Lapidus and Sokolove (1993). Change in absorbance of mitochondria was monitored at $540 \mathrm{~nm}$ using a double beam UV-visible spectrophotometer (T80 model, PG instrument UK). Mitochondrial fraction $(0.4 \mathrm{mg} / \mathrm{mL})$ was suspended in a medium containing $210 \mathrm{mM}$ mannitol, $70 \mathrm{mM}$ sucrose, $5 \mathrm{mM}$ HEPES-potassium hydroxide $(\mathrm{pH} 7.4), 0.8 \mu \mathrm{M}$ rotenone and $5 \mathrm{mM}$ succinate. MMPT was induced using sodium arsenite while spermine, a polyamine served as an inhibitor of MMPT.

\section{Statistical Analysis:-}

Statistical analysis was carried out with the aid of SPSS for Windows: SPSS Inc., Chicago, standard version 17.0 to determine difference between means using independent sample t-test. Data were reported as mean \pm standard error of mean. Data were considered significant at $\mathrm{P}<0.05$. Fifty percent inhibitory concentration $\left(\mathrm{IC}_{50}\right)$ for test fractions was calculated using GraphPad Prism ${ }^{\circledR}$ 7.00. Graphical presentations were plotted using Microsoft Excel 2013 version; Microsoft Office Suite 2013.

\section{Results:-}

Table 1 shows that the percentage yields of $G$. kola stem bark ethanolic extract and triterpenoid fraction were $32.45 \%$ and $20.17 \%$ respectively. EEGK had significantly $(\mathrm{P}<0.05)$ elevated total phenol $(0.52 \pm 0.01 \mathrm{GAE} \mathrm{mg} / \mathrm{g})$ and flavonoid $(0.34 \pm 0.04 \mathrm{QE} \mathrm{mg/g})$ contents when compared with TFGK phenol $(0.46 \pm 0.02 \mathrm{GAE} \mathrm{mg} / \mathrm{g})$ and 
flavonoid $(0.26 \pm 0.01 \mathrm{QE} \mathrm{mg/g})$ contents. In addition, tannin, saponin and alkaloid contents in pulverized G. kola stem bark were $0.06 \pm 0.01 \%, 3.33 \pm 0.40 \%$ and $1.73 \pm 0.02 \%$ respectively.

Data in Figure 1 showed that $20-100 \mu \mathrm{g} / \mathrm{mL}$ standard ascorbic acid, EEGK and TFGK significantly scavenged $(\mathrm{P}<0.05)$ DPPH radical in a concentration dependent manner. The minimum and maximum DPPH scavenging activity for standard ascorbic acid were $18 \pm 1.07 \%$ and $67.56 \pm 1.49 \%$ at 20 and $100 \mu \mathrm{g} / \mathrm{mL}$ respectively, while EEGK had $15.28 \pm 1.94 \%$ and $61.93 \pm 0.97 \%$, and TFGK had $12.41 \pm 0.84 \%$ and $41.02 \pm 1.93 \%$ at 20 and 100 $\mu \mathrm{g} / \mathrm{ml}$, respectively. Furthermore, Table 2 showed that EEGK $\left(\mathrm{IC}_{50}=79.14 \pm 0.02 \mu \mathrm{g} / \mathrm{mL}\right)$ had a higher DPPH scavenging activity than $\mathrm{TFGK}\left(\mathrm{IC}_{50}=102.1 \pm 0.01 \mu \mathrm{g} / \mathrm{mL}\right)$.

Data in Figure 2 showed that $20-100 \mu \mathrm{g} / \mathrm{mL}$ standard ascorbic acid, EEGK and TFGK significantly $(\mathrm{P}<0.05)$ scavenged hydrogen peroxide in a concentration dependent manner. The minimum and maximum hydrogen peroxide scavenging activity for standard ascorbic acid were $45.78 \pm 0.20 \%$ and $91.11 \pm 1.50 \%$ at 20 and 100 $\mu \mathrm{g} / \mathrm{mL}$ respectively while EEGK had $16.56 \pm 0.50 \%$ and $55.90 \pm 1.6 \%$, and TFGK $13.89 \pm 1.7 \%$ and $37.95 \pm 0.50 \%$ at 20 and $100 \mu \mathrm{g} / \mathrm{mL}$ respectively. Furthermore, Table 2 showed that EEGK $\left(\mathrm{IC}_{50}=94.03 \pm 1.02 \mu \mathrm{g} / \mathrm{mL}\right) \mathrm{had}$ a higher hydrogen peroxide scavenging activity than TFGK $\left(\mathrm{IC}_{50}=188.70 \pm 1.25 \mu \mathrm{g} / \mathrm{ml}\right)$.

Data in Figure 3 showed that $20-100 \mu \mathrm{g} / \mathrm{mL}$ standard ascorbic acid, EEGK and TFGK significantly $(\mathrm{P}<0.05)$ scavenged hydroxyl radical in a concentration dependent manner. The minimum and maximum hydroxyl radical scavenging activity for standard ascorbic acid were $18.22 \pm 0.34 \%$ and $75.82 \pm 2.50 \%$ at 20 and $100 \mu \mathrm{g} / \mathrm{mL}$ respectively while EEGK had $17.59 \pm 1.95 \%$ and $70.16 \pm 2.80 \%$, and TFGK $17.49 \pm 2.90 \%$ and $68.51 \pm 1.50 \%$ at 20 and $100 \mu \mathrm{g} / \mathrm{mL}$ respectively. Furthermore, Table 2 showed that EEGK $\left(\mathrm{IC}_{50}=70.08 \pm 0.11 \mu \mathrm{g} / \mathrm{mL}\right.$ ) had a higher hydroxyl radical scavenging activity than TFGK $\left(\mathrm{IC}_{50}=74.22 \pm 0.14 \mu \mathrm{g} / \mathrm{mL}\right)$. In addition, data in Figure 4 showed that EEGK $(1.11 \pm 0.01 \mathrm{mg}$ ascorbic acid equivalent/g) had a significantly $(\mathrm{P}<0.05)$ higher TFGK $(1.07 \pm 0.01 \mathrm{mg}$ ascorbic acid equivalent/g).

Table 3 shows that $10-30 \mu \mathrm{g} / \mathrm{mL}$ EEGK and TFGK inhibited arsenic-induced MMPT in a concentration dependent manner. Furthermore, $30 \mu \mathrm{g} / \mathrm{mL}$ TFGK $(\Delta 540 \mathrm{~nm}=-0.02 \pm 0.00$ and $-0.02 \pm 0.01)$ significantly $(\mathrm{P}<0.05)$ inhibited arsenic-induced liver and kidney MMPT than EEGK $(\Delta 540 \mathrm{~nm}=-0.08 \pm 0.01$ and $-0.06 \pm 0.01)$ respectively. In addition, $10-30 \mu \mathrm{g} / \mathrm{mL}$ TFGK inhibited arsenic-induced liver MMPT by 77.78 to $92.59 \%$ and arsenic-induced kidney MMPT by 61.11 to $88.89 \%$ respectively, while $10-30 \mu \mathrm{g} / \mathrm{mL}$ EEGK inhibited arsenic-induced liver MMPT by 44.44 to $70.37 \%$ and arsenic-induced kidney MMPT by 50.00 to $66.67 \%$ respectively. Spermine also inhibited arsenite-induced liver $(\Delta 540 \mathrm{~nm}=-0.05 \pm 0.02)$ and kidney $(\Delta 540 \mathrm{~nm}=-0.04 \pm 0.01)$ MMPT by $81.48 \%$ and $77.78 \%$ respectively.

Table 1:- Quantitative phytochemical analysis of G. kola stem bark.

\begin{tabular}{|c|c|c|}
\hline Test parameters & EEGK & TFGK \\
\hline Total Phenols (GAE mg/g extract) & $0.52 \pm 0.01^{*}$ & $0.46 \pm 0.02$ \\
\hline Flavonoids (QE mg/g extract) & $0.34 \pm 0.04^{*}$ & $0.26 \pm 0.01$ \\
\hline Tannin content (\%) & Pulverized G. kola stem \\
\hline Saponin content (\%) & $0.06 \pm 0.01$ & \\
\hline Alkaloid content (\%) & $3.33 \pm 0.40$ & \\
\hline Percentage yield & $1.73 \pm 0.02$ & \\
\hline
\end{tabular}

GAE: - Gallic acid Equivalent QE: - Quercetin Equivalent; * indicates significantly elevated when compared with TFGK at $\mathrm{P}<0.05$; Values were expressed as mean \pm standard error of the mean (SEM) $(n=3)$. EEGK: - Ethanolic extract of G. kola stem bark; TFGK: - Triterpenoid fraction of G. kola stem bark

Table 2:- Fifty percent inhibitory concentration $\left(\mathrm{IC}_{50}\right)$ values for ascorbic acid, EEGK and TFGK in different antioxidant models.

\begin{tabular}{|c|c|c|c|}
\hline \multirow{2}{*}{ Test samples } & \multicolumn{3}{|c|}{$\mathbf{I C}_{\mathbf{5 0}}(\boldsymbol{\mu g} / \mathbf{m L} \mathbf{)}$} \\
\cline { 2 - 4 } & DPPH & HPSA & HRSA \\
\hline Ascorbic acid & $67.96 \pm 0.01$ & $26.08 \pm 0.07$ & $58.84 \pm 0.05$ \\
\hline EEGK & $79.14 \pm 0.02^{*}$ & $94.03 \pm 1.02^{*}$ & $70.08 \pm 0.11^{*}$ \\
\hline TFGK & $102.10 \pm 0.01$ & $188.70 \pm 1.25$ & $74.22 \pm 0.14$ \\
\hline
\end{tabular}

* indicates significantly reduced when compared with TFGK at $\mathrm{P}<0.05$ 
DPPH: - 1-1- diphenyl 2-picryl hydrazyl radical scavenging activity

HRSA: - Hydroxyl radical scavenging assay

HPSA: - Hydrogen peroxide scavenging activity

EEGK: - Ethanolic extract of G. kola stem bark

TFGK: - Triterpenoid fraction of G. kola stem bark

Table 3:- Inhibitory effects of varying concentrations of ethanolic extract of $G$. kola stem bark (EEGK) and triterpenoid fraction of G. kola stem bark (TFGK) on sodium arsenic-induced liver and kidney MMPT energized by succinate for $12 \min$ at $\Delta 540 \mathrm{~nm}$.

\begin{tabular}{|c|c|c|c|c|}
\hline \multirow{2}{*}{ Parameters } & \multicolumn{2}{|c|}{$\begin{array}{c}\text { Inhibition of arsenite- } \\
\text { Induced liver MMPT }\end{array}$} & \multicolumn{2}{c|}{$\begin{array}{c}\text { Inhibition of arsenite-induced } \\
\text { kidney MMPT }\end{array}$} \\
\cline { 2 - 5 } & Absorbance at $\Delta \mathbf{5 4 0} \mathbf{~ n m}$ & $\mathbf{\%}$ & Absorbance at $\Delta \mathbf{5 4 0} \mathbf{~ n m}$ & \% \\
\hline $5 \mu \mathrm{g} / \mathrm{mL}$ Arsenic & $-0.27 \pm 0.01^{\mathrm{e}}$ & - & $-0.18 \pm 0.02^{\delta}$ & - \\
\hline $10 \mu \mathrm{g} / \mathrm{mL} \mathrm{Spermine}$ & $-0.05 \pm 0.02^{\mathrm{bc}}$ & 81.48 & $-0.04 \pm 0.01^{\beta}$ & 77.78 \\
\hline $10 \mu \mathrm{g} / \mathrm{mL}$ EEGK & $-0.15 \pm 0.02^{\mathrm{d}}$ & 44.44 & $-0.09 \pm 0.01^{\gamma}$ & 50.00 \\
\hline $20 \mu \mathrm{g} / \mathrm{mL}$ EEGK & $-0.09 \pm 0.02^{\mathrm{c}}$ & 66.67 & $-0.08 \pm 0.01^{\beta \gamma}$ & 55.56 \\
\hline $30 \mu \mathrm{g} / \mathrm{mL}$ EEGK & $-0.08 \pm 0.01^{\mathrm{c}}$ & 70.37 & $-0.06 \pm 0.01^{\beta}$ & 66.67 \\
\hline $10 \mu \mathrm{g} / \mathrm{mL}$ TFGK & $-0.06 \pm 0.02^{\mathrm{c}}$ & 77.78 & $-0.07 \pm 0.02^{\beta \gamma}$ & 61.11 \\
\hline $20 \mu \mathrm{g} / \mathrm{mL}$ TFGK & $-0.04 \pm 0.01^{\mathrm{bc}}$ & 85.19 & $-0.04 \pm 0.01^{\beta}$ & 77.78 \\
\hline $30 \mu \mathrm{g} / \mathrm{mL}$ TFGK & $-0.02 \pm 0.00^{\mathrm{a}}$ & 92.59 & $-0.02 \pm 0.01^{\alpha}$ & 88.89 \\
\hline
\end{tabular}

Different letters and symbols across columns denotes significantly higher inhibition of MMPT at $\mathrm{P}<0.05$

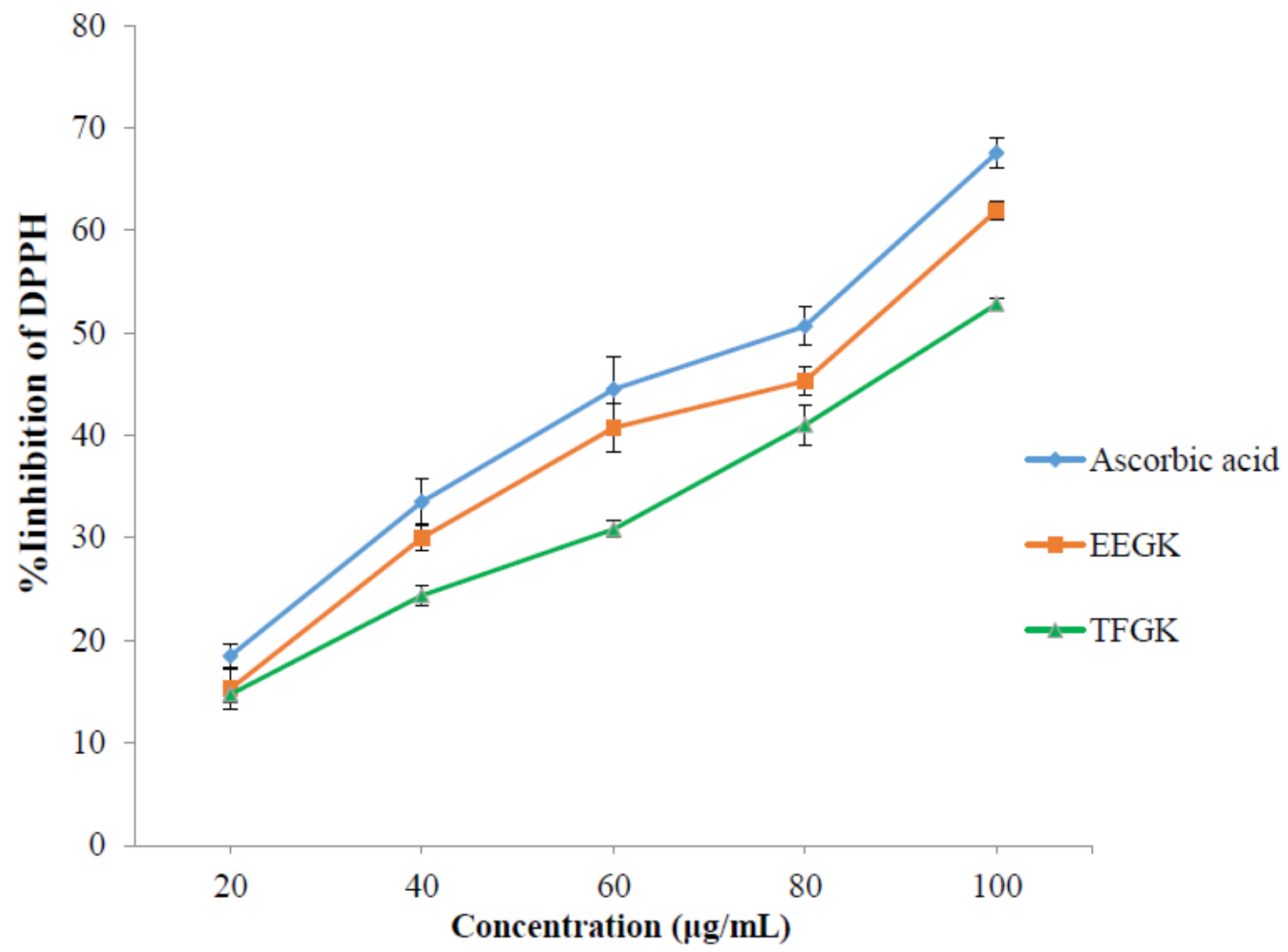

Figure 1:- DPPH radical scavenging activities of ethanolic extract of G. kola stem bark (EEGK) and triterpenoid fraction of G. kola stem bark (TFGK) 


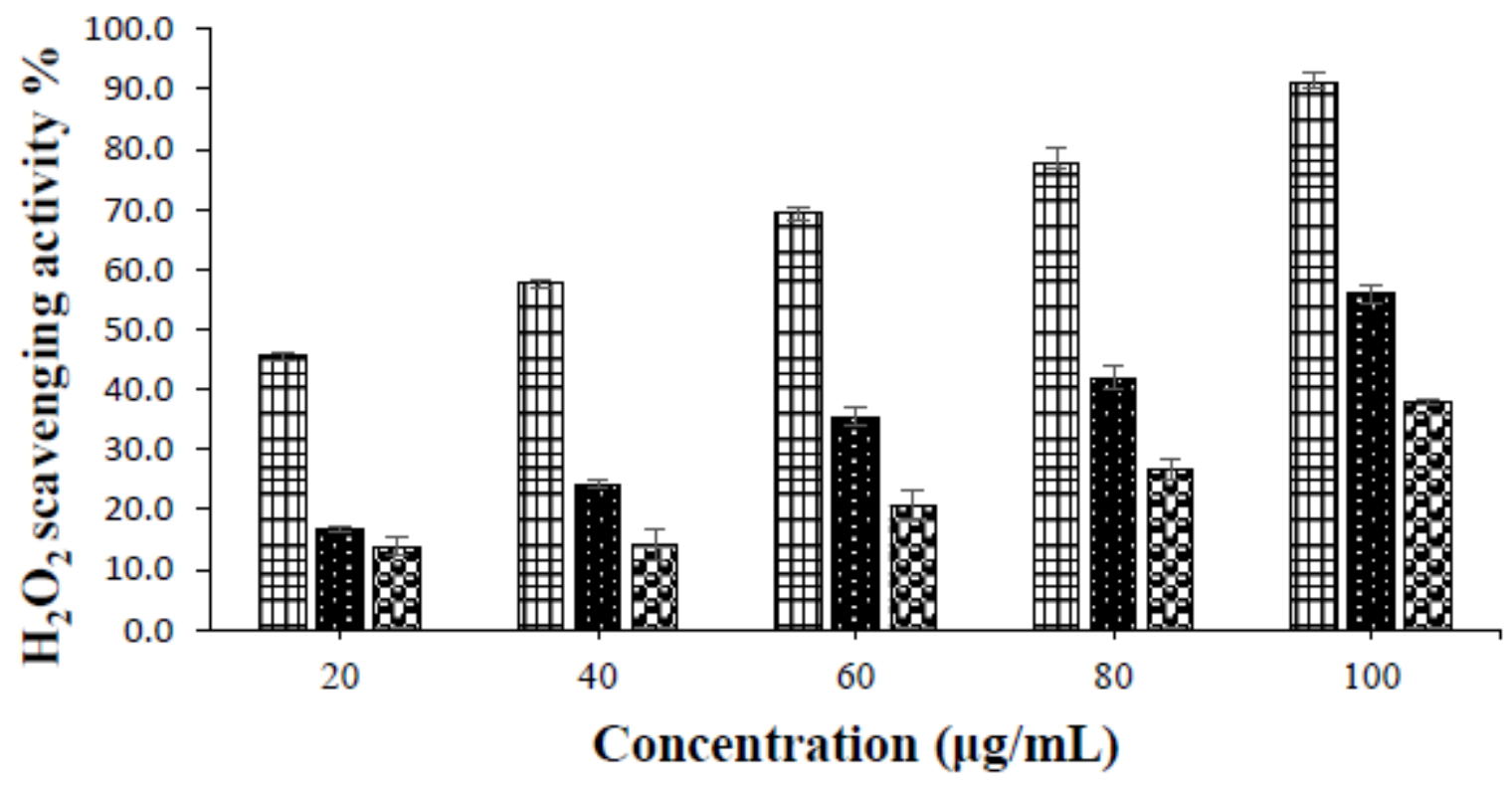

\section{$\boxplus$ Ascorbic acid aEGK $\quad$ a TFGK}

Figure 2:- Hydrogen peroxide scavenging activities of ethanolic extract of G. kola stem bark (EEGK) and triterpenoid fraction of G. kola stem bark (TFGK)

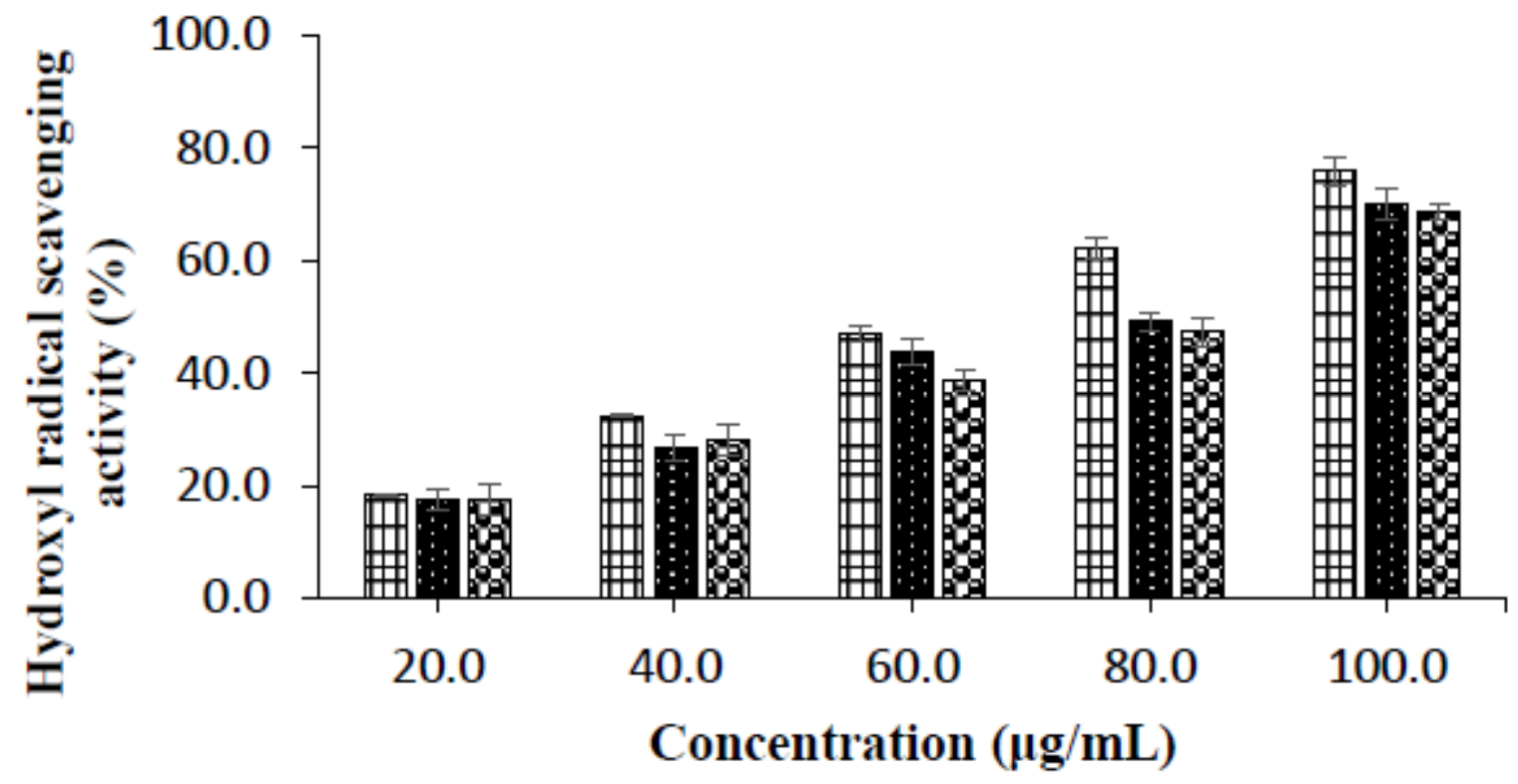

\section{由 Ascorbic acid EEGK $\mathbf{a}$ TFGK}

Figure 3:- Hydroxyl radical scavenging activities of ethanolic extract of G. kola stem bark (EEGK) and triterpenoid fraction of G. kola stem bark (TFGK) 


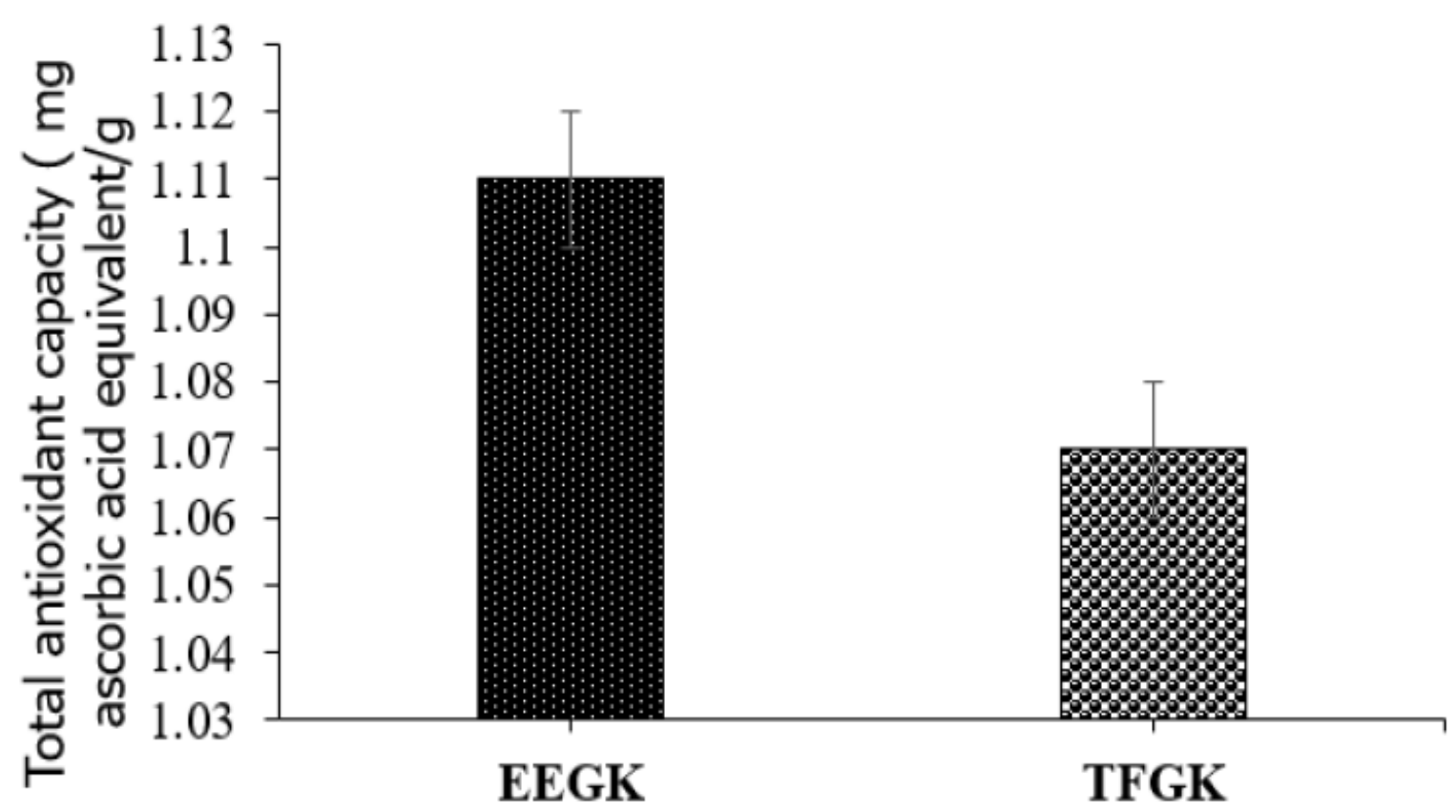

\section{Test samples}

Figure 4:- Total antioxidant capacity (TAC) of activities of ethanolic extract of G. kola stem bark (EEGK) and triterpenoid fraction of $G$. kola stem bark (TFGK).

\section{Discussion:-}

In this present study, appreciable quantities of flavonoids, phenols, tannins, saponins and alkaloids were detected in EEGK and TFGK. This suggested that $G$. kola stem bark could possess bioactive compounds. The presence of these phytochemicals might explain the rationale for the ethnomedical use of $G$. kola stem bark as therapy against metalinduced liver and kidney toxicities. Previous study had shown that flavonoids possess the capacity to scavenge reactive chemicals, including hydrogen peroxide, hydroxyl radicals, lipid peroxyl radicals and superoxide anions (Buhian, 2016). These chemical radicals are unstable molecules with the propensity to abstract electrons from tissue macromolecules thereby eliciting deleterious effects on biochemical systems (Tentscher, 2013). Furthermore, phenols, flavonoids, tannins, and saponins present in plant materials had been reported to elicit hepatoprotective, nephroprotective, anti-inflammatory and antioxidant activities (Osadeba, 2012). These notable biological effects might be due to the presence of functional moieties which confers protection to the body system against the insurgence of deleterious reactive chemical species (Araujo et al., 2015).

Data from this study showed that the EEGK contained higher total phenol and flavonoid contents than TFGK. This suggested that EEGK could possess higher antioxidant and anti-inflammatory activities than TFGK. Previous study had reported that the solvent ethanol has a higher extractive capacity to penetrate the cell wall of plant materials to isolate mostly polar phyto-compounds, including phenols and some flavonoids than non-polar solvents (Sharmin et al., 2016). Furthermore, to gain some insight as to the antioxidant potentials of EEGK and TFGK, selected in vitro antioxidant models were adopted. The study showed that EEGK consistently exhibited a higher radical scavenging activity than TFGK for DPPH, hydrogen peroxide, hydroxyl radical and total antioxidant capacity assays. This indicated that EEGK possesses higher antioxidant activity than TFGK. This effect could be attributed to the presence of phenolic and flavonoid compounds and the obtained data seems to be in agreement with higher total phenol and flavonoid contents in EEGK than TFGK. Previous study had reported that plant extracts with antioxidant activity have the capacity to readily release proton $(\mathrm{s})\left(\mathrm{H}^{+}\right)$to neutralize the unstable chemical species. This is also corroborated by the reports that ascorbic acid exerts antioxidant action by donating protons to neutralize free radicals (Shalaby and Shanab, 2013).

Further study showed the capacities of EEGK and TFGK to reverse arsenic-induced liver and kidney mitochondrial membrane permeability transitions (MMPTs). Arsenic induced MMPT has been implicated as a molecular marker 
for arsenic tissue toxicity (Selvaraj et al., 2013). Data in this present study showed that the different concentrations of EEGK and TFGK inhibited arsenic-induced liver and kidney MMPTs in a concentration-dependent manner. This suggested that the EEGK and TFGK contained mitochondrial protective compounds against arsenic-induced liver and kidney toxicities. Previous study had reported that sodium arsenic inhibited complex I and II leading to the disruption of mitochondrial electron transport chain, altering the bioenergetics status with the formation of mitochondrial reactive oxygen species (ROS) inducing MMPT with subsequent activation of apoptotic pathway (Hosseini et al., 2013). However, phenol and flavonoid antioxidants present in plant extracts have been previously shown to act as scavengers of mitochondrial ROS and inhibitors of MMPT (Anyasor et al., 2014; Katerina and Gonzola, 2016). Percentage inhibitions of arsenic-induced liver and kidney MMPTs by TFGK were found to be higher when compared to EEGK and natural MMPT inhibitor, spermine. This indicated that TFGK possesses a higher ameliorative effect against arsenic-induced mitochondrial membrane perturbation than EEGK. This observation could account for one of the possible molecular events associated with the previously reported hepatoprotective and nephroprotective properties of G. kola stem bark against arsenic-induced tissue damages. More so, the inhibition of arsenite-induced liver and kidney MMPTs by TFGK might be through metal chelation than antioxidant activity or a combination of both properties.

\section{Conclusion:-}

It is therefore recommended that the triterpenoid fraction of $G$. kola stem bark be further explored as a potential source for $\operatorname{drug}(\mathrm{s})$ to be used as therapy against arsenic elicited tissue toxicity. In addition, data from this study has provided some scientific insight to explain the ethnomedical use of $G$. kola stem bark as therapy for liver and kidney dysfunctions.

\section{Conflict of interest:-}

Authors declare that there are no known conflicts of interest of interest with regards to the writing and financing of this research work.

\section{Acknowledgements:-}

The authors express gratitude to Babcock University Administration and College of Postgraduate Studies for their support towards this study. Professor F.D. Onajobi and the entire members of Biochemistry Department are appreciated for technical input during the execution of this project. We are grateful to Chiamaka O. Anyasor for the proof reading of the manuscript.

\section{References:-}

1. Adesina, S. K., Z. O. Gbile, O. A. Odukoya, D. D. Akinwusi, H. C. Illoh, and A. A. Yeola. 1995. Survey of indigenous useful plants of West Africa with special emphasis on medicinal plants and issues associated with management, The United Nations Programme on Natural Resources in Africa.

2. Anyasor, G. N., F. D. Onajobi, O. Osilesi, and O. Adebawo. 2014. Hexane fraction of Costus afer ker Gawl leaves inhibited mitochondrial membrane permeability transition, $\mathrm{F}_{1} \mathrm{~F}_{0}$ Adenosine triphosphatase and scavenged nitric oxide and hydrogen peroxide, J. Investigational Biochem. 3:78-84.

3. Araujo, M., B. Filipa, R. C. Alves, and S. Pimentel. 2015. Phenolic compounds from olive mill wastes: health effects, analytical approach and application as food antioxidants. Trends Food Sci. Technol. 45:200-211.

4. Bishayi, S. 2000. Sodium arsenite induced alteration in functional activity of murine peritoneal macrophages. Indian J. Pharmacol. 32:192-197.

5. Buhian, W. P. 2016. Bioactive metabolite profiles and antimicrobial activity of ethanolic extracts from Muntingia calabura L. leaves and stems. Asian Pac. J. Trop. Biomed. 6:682-685.

6. Bustamante, J., L. Nutt, S. Orrenius, and V. Gogvadze. 2005. Arsenic stimulates release of cytochrome c from isolated mitochondria via induction of mitochondrial permeability transition, Toxicol. Appl. Pharmacol. 207:110-116.

7. Chandranayagam, C., G. Veeraraghavan, A. Subash, and H. R. Vasanthi. 2013. Restoration of arsenite induced hepato-toxicity by crude tannin rich fraction of Theobroma cacao in Sprague Dawley rats. Food Res. Int. 50:4654.

8. Chavan, H., P. Christudoss, K. Mickey, R. Tessman, H. Ni, R. Swerdlow, and P. Krishnamurthy. 2017. Arsenite effects on mitochondrial bioenergetics in human and mouse primary hepatocytes follow a nonlinear dose response. Oxid. Med. Cell. Longev. https://doi.org/10.1155/2017/9251303. 
9. Farombi, E. O., and O. Owoeye. 2011. Antioxidative and chemopreventive properties of Vernonia amygdalina and Garcinia biflavonoid. Int. J. Environ. Res. Public Health 8:2533-2555.

10. Flora, S. J., A. Mehta, and R. Gupta. 2009. Prevention of arsenic-induced hepatic apoptosis by concomittant administration of garlic extracts in mice. Chem. Biol. Interact. 177:227-233.

11. Halliwell, B., J. M. Guttridge, and O. I. Aruoma. 1987. The deoxyribose method: a simple "test-tube" assay for determination of rate constants for reactions of hydroxyl radicals. Anal. Biochem. 165: 215-219.

12. Hogeboom, G. H., W. C. Schneider, and G. E. Pallade. 1948. Cytochemical studies of mammalian tissues; isolation of intact mitochondria from rat liver; some biochemical properties of mitochondria and submicroscopic particulate material. J. Biol. Chem. 172:619-635.

13. Hosseini, M. J., F. Shaki, M. Ghazi-Khansari, and J. Pourahmad. 2013. Toxicity of arsenic (III) on isolated liver mitochondria: A new mechanistic approach. Iranian J. Pharma Res. 12:121-138.

14. Iwu, M. M.1993. Handbook of African Medicinal Plants. Boca Raton, Florida: CRC Pres,

15. Juliana, A., S. Moctar, and K. Christopher. 2006. Garcinia kola Heckel, Forest and Landscape 2:264-269.

16. Iwu, M. M., O. A. Igboko, C. O. Okunji, and M. S. Tempesta. 2009. Antidiabetic and aldose reductase activities of Biflavanones of Garcinia kola. J. Pharm. Pharmacol. 42:290-292.

17. Jomova, K., Z. Jenisova, M. Feszterova, S. Baros, J. Liska, D. Hudecova, C. J. Rhodes, and M. Valko. 2011. Arsenic: toxicity, oxidative stress and human disease. J. Appl. Toxicol. 31:95-107.

18. Kapaj, S., H. Peterson, K. Liber, and P. Bhattacharya. 2006. Human health effects from chronic arsenic poisoning-a review. J. Environ. Sci. Health, Part A 41:2399-2428.

19. Katerina, K., and C. Gonzola. 2016. Singlet oxygen: applications in biosciences and nanosciences. Royal Soc. Chem. 1:12-25.

20. Kitchin, K. T. 2001. Recent advances in arsenic carcinogenesis: modes of action, animal model systems, and methylated arsenic metabolites. Toxicol. Appl. Pharmacol. 172:249-261.

21. Kulp, R. T., H. E. Shelley, and O. S. Ronald. 2004. Redox transformations of arsenic oxyanions in periphyton communities. Appl. Environ. Microbiol. 70:6428-6434.

22. Lapidus, R. G., and P. M. Sokolove. 1993. Spermine inhibition of the permeability transition of isolated rat liver mitochondria: an investigation of mechanism. Arch. Biochem. Biophys. 306:246-253.

23. Lowry, O. H., N. J. Rosebrough, A. L. Farr, and R. J. Randall. 1951. Protein measurment with folin phenol reagent. J. Biol. Chem. 193:265-275.

24. Mensor, L. I., F. S. Menezes, G. G. Leitao, A. S. Reis, T. C. Santos, C. S. Coube, and S. G. Leitao. 2001. Screening of Brazilian plant extracts for antioxidant activity by the use of DPPH free radical method. Phytother. Res. 15:127-130.

25. Nasri, H., and H. Shirzad. 2013. Toxicity and safety of medicinal plants. J. HerbMed Pharmacol. 2:21-23.

26. National Research Council. 2011. Guide for the Care and Use of Laboratory Animals (8 ed.). Washington D.C. The National Academies Press.

27. Noha, A., I. A. Mohammed, A. Mohamed, and E. B. Elfadil. 2011. Nutritional evaluation of sorghum flour (Sorghum bicolor L. Moench) during processing of Injera. World Academy Sci. Engin. Technol. 75:86-112.

28. Okwu, D. E., and C. Josiah. 2006. Evaluation of the chemical composition of two Nigerian medicinal plants. Afr. J. Biotechnol. 5:357-361.

29. Onyilagba, J. C., and S. Islam. 2011. Flavonoids and other polyphenols of the cultivated species of the genus phaseolus. Int. J. Agric. Bol. 11:231-234.

30. Ordonez, A. L., J. D. Gomez, M. A. Vattuone, and M. I. Isla. 2006. Antioxidant Activities of Sechium edule (Jacq). Food Chem. 97:452-458.

31. Osadeba, P. O. 2012. Phytochemical analysis, hepatoprotective and antioxidant activity of Alchornea cordifolia methanol leaf extract on carbon tetrachloride-induced hepatic damage in rats. Asian Pac. J. Trop. Med. 5:289293.

32. Pramod, C., M. V. Neethu, V. M. Anjumol, A. Vysakh, and R. Selvaraj. 2016. Triterpenoid fraction isolated from Euphorbia tirucalli Linn. ameliorates collagen induced arthritis in Wistar rats. J. Appl. Pharma. Sci. 6:7075. doi:10.7324/JAPS.2016.600112.

33. Priesto, P., M. Pineda, and M. Aguilar. 1999. Spectrophotometric quantitation of antioxidant capacity through the formation of phosphomolybdenum complex: specific application to the determination of vitamin E. Anal. Biochem. 269:337-341.

34. Rao, V. K., E. A. Carlson, and S. S. Yan. 2014. Mitochondrial permeability transition pore is a potential drug target for neurodegeneration. Biochimi. Biophys. Acta (BBA)-Mol. Basis Dis. 1842:1267-1272.

35. Ruch, R. J., S. J. Cheng, and J. E. Klaunig. 1989. Prevention of cytotoxicity and inhibition of intracellular communication by antioxidant catechins isolated from chinese green tea. Carcinogenesis 10:1003-1008. 
36. Santra, A., A. Maiti, S. Das, S. Lahiri, S. K. Charkaborty, and D. N. Mazumder. 2000. Hepatic damage caused by chronic arsenic toxicity in experimental animals. J. Toxicol. Clin. Toxicol. 38:395-405.

37. Schmeisser, S., K. Schmeisser, S. Weimer, M. Groth, S. Priebe, E. Fazius, D. Kuhlow, J.W. Einax, R. Guthke, M. Platzer, K. Zarse, and M. Ristow. 2013. Mitochondrial hormesis links low-dose arsenite exposure to lifespan extension. Aging Cell. 12:508-517.

38. Selvaraj, V., M. Cohenford, M. Y. Armistead, and E. Murray. 2013. Arsenic trioxide (As2O3) induces apoptosis and necrosis mediated cell death through mitochondrial membrane potential damage and elevated production of reactive oxygen species in PLHC-1 fish cell line. Chemosphere 1201-1209. doi:10.1016/j.chemosphere.2012.09.039.

39. Shalaby, E. A., and S. M. Shanab. 2013. Antioxidant compounds, assays of determination and mode of action. Afr. J. Pharm. Phamacol. 7:528-539.

40. Sharmin, T., N. Ahmed, A. Hossain, M. M. Hossain, S. C. Mondal, M. R. Haque, M. Almas, and M. A. B. Siddik. 2016. Extraction of bioactive compound from some fruits and vegetables (pomegranate peel, carrot and tomato). Am. J. Food Nutr. 4:8-19.

41. Shi, H., Shi, X., and K. J. Liu. 2004. Oxidative mechanism of arsenic toxicity and carcinogenesis. Mol. Cell. Biochem. 255:67-78.

42. Singleton, V. L., R. Orthofer, and R. M. Lamuela-Ruventos. 1999. Analysis of total phenols and other oxidation substrates and antioxidants by means of folin-ciocalteu reagent. Methods Enzymol. 299:152-178.

43. Tapio, S., and B. Grosche. 2006. Arsenic in the aetiology of cancer. Mutat. Res. 612:215-246.

44. Tentscher, P. R. 2013. On the nature of interactions of radicals with polar molecules. J. Phys. Chem.117:1256012568.

45. World Health Organization. 2004. Environmental Health Criteria 224: Arsenic and arsenic compounds. http://www.who.int/ipcs. Retrieved on April, 2016. 